\title{
GRAVITY CHANGES ASSOCIATED WITH SEISMIC ACTIVITIES
}

\author{
Yukio HaGIWARA \\ Earthquake Research Institute, University of Tokyo, \\ Tokyo, Japan \\ (Received April 15, 1977; Revised July 30, 1977)
}

\begin{abstract}
Repeated gravity surveys have been carried out in several places for the purpose of detecting small changes in gravity accompanied with seismic land-deformations and faulting motions. Statistically significant gravity changes were found during the 1964 Niigata earthquake and the 1963-67 volcanic activities in Oshima Island. On the basis of the gravity-elevation relation, many authors estimated crustal density change induced by the Matsushiro earthquake swarm.

A recent highlight in gravimetric work is a gravity decrease with a free-air rate over the earthquake swarm area in the eastern part of Izu Peninsula. The rounded dome-like gravity-decreasing area has been gradually extended in a N-S direction. Another topic is a tidal gravity change recorded by an Askania gravimeter in the epicentral area during the 1974 Izu Hanto-oki earthquake. The postseismic change in daily-mean tidal factor, ranging from 1.1 to 1.6, was correlated with daily maximum amplitude of volcanic tremor observed beside the crater of Oshima Island, $40 \mathrm{~km}$ distant from the tidal station.
\end{abstract}

\section{Introduction}

The Imperial Earthquake Investigation Committee was organized for promoting earthquake researches and disaster prevention immediately after the 1891 Nobi earthquake. The long-term plan of the committee, which was subsequently presented to the Minister of Education in 1893, emphasized that earthquake researches should cover not only seismology but also general earth sciences, including "gravity change."

Many Japanese geophysicists have waited for an opportunity to seize a gravity change concurrent with an earthquake. However, pendulum apparatus used in the past was so insensitive to a small gravity change that such an opportunity had never come till sensitive spring-type gravimeters were utilized for gravity surveys. A portable high-sensitive gravimeter facilitates a comparison of gravity values before and after an earthquake for detecting the earthquake-induced gravity change. As a matter of fact, the number of reports of gravity change has rapidly increased in Japan since LaCoste and Romberg gravimeters were imported.

The aim of this review article is, first of all, to outline gravity-change work in Japan. Special mention will be made of gravity changes associated with the rounded dome-like uplift in the eastern part of Izu Peninsula. Possible causes of the uplift will be presumed as a Mogi model (Mogr, 1958) in the following section. Finally, 
we present a short report on a tidal gravity change observed in the epicentral area of the 1974 Izu Hanto-oki earthquake.

\section{Pre-Matsushiro and Matsushiro Gravity-Change Work}

The Riefler pendulum clock in the Tokyo Astronomical Observatory had a tendency to gain after the 1923 Kanto earthquake. It was then supposed that this phenomenon might be caused by an earthquake-induced gravity change amounting to 10 mgals. A paper on the possibilities of earthquake-induced gravity change, which was submitted by IsHrmoto (1929) to Vol. 1 of Zishin (the Journal of the Seismological Society of Japan), is the first investigation of gravity change in Japan. It was later proved by gravity-pendulum measurements relative to Sendai and Mizusawa that such a large change in gravity had never taken place in Tokyo during the Kanto earthquake.

The advancement in techniques of manufacturing spring-type gravimeters, highly sensitive and convenient for field uses, encouraged Japanese geophysicists to tackle gravity change. In the hope that the crustal movement induced by a large earthquake could easily be checked by comparing gravity values measured before and after the earthquake, and that repeated surveys over a volcano might disclose the effect of an abundance of effused lava on the gravity field, they searched for gravity changes during the 1949 Imaichi earthquake of magnitude 6.4 on Gutenberg-Richter scale (IrDA et al., 1950), the 1950-51 volcanic activity in Oshima Island (Irda et al., 1951), the earthquake of magnitude 6.5 in the northern part of Miyagi Prefecture in 1962 (JitsukaWA and TAJIMA, 1962), etc.

There is a phenomenon called "drift" that is critical for the use of a gravimeter reading. If the quantity of drift is neither small nor linear with time, an accurate determination of gravity change may be impossible. The linearity is not so good for the early spring-type gravimeters, but recently-manufactured LaCoste and Romberg gravimeters have the advantage of small amounts of drift linearly increasing with time, in the order of $10 \mu$ gals a day or less. The uncertainties in gravity change obtained with this type of gravimeter are estimated as less than $20 \mu$ gals. The Geographical Survey Institute (GSI) detected gravity changes ranging from -0.30 to 0.25 mgals during the 1964 Niigata earthquake by means of a LaCoste and Romberg gravimeter (FUJI, 1966). The fact that the gravity changes were concentrated mainly in the Shinano riverside areas was explained as change in groundwater level in the sandy soil.

The 1965-67 Matsushiro earthquake swarm provided an opportunity to test the applicability of gravity-change measurement to tectonic studies. Gravity change is caused by a combined effect of changes in elevation with those in apparent crustal density. The combination of leveling and gravity data may possibly play an important role in disclosing the coswarm density change, i.e., the swarm source mechanism. The Earthquake Research Institute (ERI) repeated both leveling and gravity surveys over the epicentral area of the swarm, while the adjacent area was 
allotted to the GSI. Both the surveys have been successively made after the coswarm crustal movement turned from uplift to subsidence. A part of the ERI leveling data (TsuboKaWA et al., 1968) has lately been corrected because of a computational mistake (IzUTUYA, 1975). TAJIMA and IzUTUYA (1974) have tabulated the ERI gravity-change data.

The GSI data at the Matsushiro first-order gravity station showed the free-air rate gravity decrease in the first stage of the swarm activity. The second stage was characterized by the Bouguer-rate gravity decrease, which can be explained as groundwater saturation in the upper crust. In the final stage after spring flow of mineral water along the faulting zone, ground subsidence generated a gradual gravity increase. Nur (1974) tried to confirm a dilatancy-fluid diffusion model on the basis of the GSI data. Based on the same data, Stuart and Johnston (1975) discussed the possibilities of magma intrusion into the focal region. KIssLINGER (1975) verified dilatancy occurrence by combining the GSI data with the lately-revised ERI data. Fujita and FujII (1974) also proposed a conceivable dilatancy process by using the data compiled by FuJI et al. (1974).

\section{Post-Matsushiro Gravity Changes}

Post-Matsushiro gravity-change work was first devoted to studies on the behavior of drift and tare of gravimeters. Laboratory and field tests were made by the Working Group for Gravity Survey and Precise Leveling with the support of the Geodetic Society of Japan. In conclusion, if we use two or three well-calibrated LaCoste and Romberg gravimeters with the utmost care for survey work, the detection of gravity change with an accuracy of $10 \mu$ gals is possible. Since then, the number of gravitychange surveys has remarkably increased. Figure 1 shows areas of gravity-change surveys conducted since the 1964 Nigata earthquake.

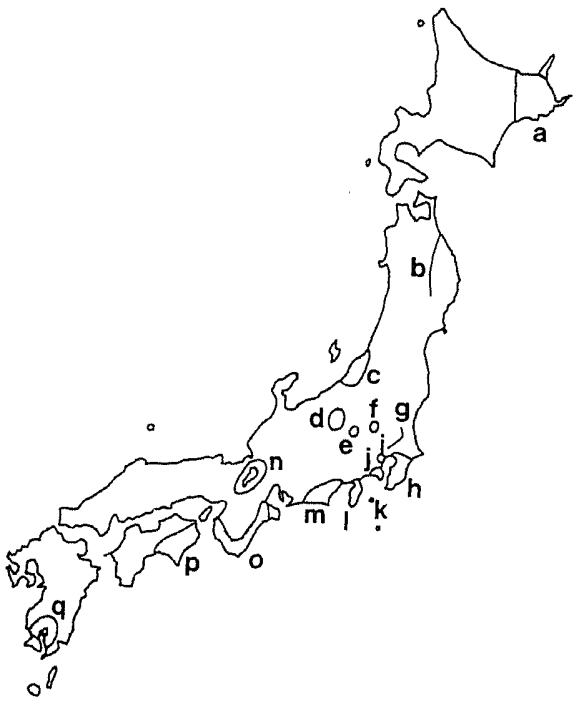

Fig. 1. Areas of gravity-change survey conducted since the 1964 Niigata earthquake. a) Nemuro Peninsula, b) Mizusawa Calibration Line, c) Niigata, d) Matsushiro, e) Volcano Asama, f) Ashio-Nikko, g) Kakioka Calibration Line, h) Boso Peninsula, i) Kawasaki, j) Miura Peninsula, k) Oshima Island, 1) Izu Peninsula, m) Tokai District, n) Lake Biwa, o) Kii Peninsula, p) Cape Muroto, q) Aira Caldera. 
The tip of Miura and Boso Peninsulas uplifted 1 to $2 \mathrm{~m}$ at the time of the 1923 Kanto earthquake. Afterwards, the uplift areas have gradually subsided with a speed of $1 \mathrm{~cm} /$ year. In 1969, a releveling brought out an anomalous land-uplift over the peninsulas. As it is feared that such an uplift might be an effect prior to a largescale earthquake, the earthquake prediction project called "Operation South Kanto" was set up (RIKITAKE, 1972). Participating in the project, the ERI established gravity coverage over the peninsulas. The gravity changes in both the peninsulas were amazingly coincident with the level change. However, the gravity changes were about several times larger than what we expected from the corresponding level changes. The cause of such large changes in gravity has not as yet been accounted for properly.

A similar gravity-elevation tendency is found around Lake Biwa, the largest lake in Japan, which is historically wellknown as the site of frequent destructive earthquakes. As the recurrence of a large earthquake there was considered possible, prediction-oriented researches were provided over the lakeside area. Gravity surveys have repeatedly conducted concurrently with leveling surveys since 1950 by means of North-American gravimeters (ICHINOHE, 1955) and later by means of LaCoste and Romberg gravimeters (SATOMURA and NAKAGAWA, 1972).

Cape Muroto, Shikoku Island, has almost periodically uplifted at the time of a large earthquake. The last uplift amounting to about $1.2 \mathrm{~m}$ was observed there when the Nankaido earthquake attacked in 1946. The post-seismic gradual land-sinking has been found by successively made leveling surveys. Precise gravity surveys have also been repeated in the hope of detecting gravity changes which might be accompanied by the land-sinking.

The 1973 Nemuro-oki earthquake, Hokkaido Island, produced an extensive subsidence. The 1962 GSI gravity data together with the 1970 leveling data were available for checking the gravity-elevation relation by comparing with the postearthquake data obtained immediately and one year after the earthquake.

A number of leveling surveys have been carried out along the Tokyo Bay coast at short time intervals in order to check ground subsidence caused by the underground water withdrawal for industrial uses. Regulation law has effectively made the sinking speed low. In Kawasaki City, very close to Tokyo, the subsidence stopped in 1960's and turned into uplift in 1970. The uplift has grown into a rounded dome with a diameter of $10 \mathrm{~km}$ or more around the mouth of Tama River. Although uplift is not always an effect precursory to a large earthquake, and the Kawasaki uplift was most probably caused by the rise of the groundwater level, we concentrated there many kinds of prediction-oriented measurements, including gravimetry.

\section{Gravity Change in the Eastern Part of Izu Peninsula}

The 1974 Izu Hanto-oki earthquake of magnitude 6.9 occurred with a rightlateral strike-slip motion of the Irozaki Fault extending to the southeast across the tip of Izu Peninsula. The aftershocks took place with a maximum depth of $10 \mathrm{~km}$ 
along the fault and the conjugate fault. GSI and ERI leveling resurveys detected an uplift amounting to about $10 \mathrm{~cm}$ at maximum in the eastern part of the epicentral area, in contrast with the subsidence of the same order found in the western part. A gravity resurvey also covered the peninsula and obtained gravity changes corresponding to the uplift-subsidence pattern.

When the aftershock activities stopped, an earthquake swarm newly took place around Mt. Togasa, in the eastern part of Izu Peninsula. Soon afterwards the swarm area was extended to the central part and the eastern coast. The GSI leveling resurvey found a rounded dome-like uplift about $20 \mathrm{~km}$ across centering at Hiekawa Pass several kilometers northwest from the swarm area. The top of the dome lifted up to $15 \mathrm{~cm}$ relative to the 1969 leveling result. Judging frcm tide gauge data, it was presumed that the uplift started at the end of 1974. At the time of the 1930 Ito earthquake swarm, a similar uplift was observed along the Izu eastern coastline, and then most probably Hiekawa Pass and its adjacent areas uplifted.

Meanwhile, the ERI resurveyed gravity in the central and eastern parts of the peninsula, discovering a similar dome-like gravity-decreasing area as shown in Fig. 2 , the pattern of which was amazingly coincident with that of the uplift. The gravity change reached $-31 \mu$ gals near the top of the uplift with the free-air relationship between gravity change and elevation change.

This uplift is located in the volcanic region. The last volcanic activity is geologically presumed to be about 4,000 years ago. The present activity may be just a revival of one of the magma chambers. The shape of the dome can be analyzed by the Mogi model (Mogr, 1958). Mogi's method is an important approach to such a problem on the basis of the elastic deformation theory of a semi-infinite solid with a spherical cavity. Let $r$ be the horizontal distance from the top of the dome. The uplift at a point $r$ is expressed as

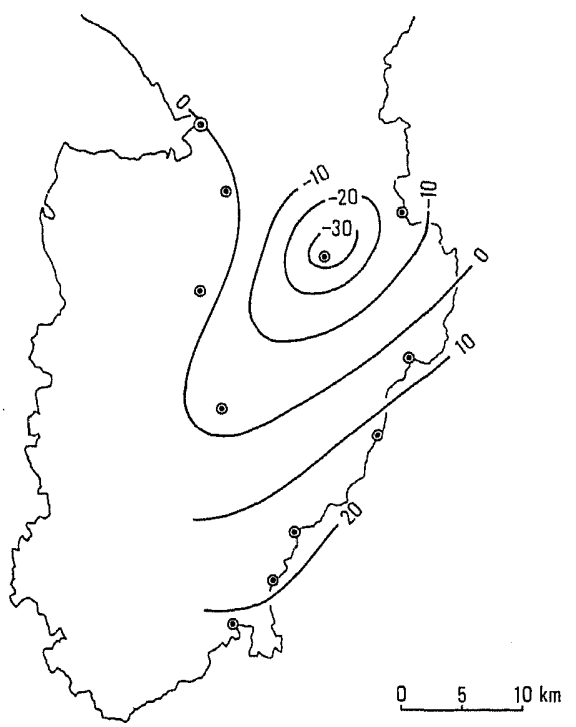

Fig. 2. Gravity change in microgals from Dec. 1974 to Mar. 1976, Izu Peninsula. 


$$
\Delta h=\frac{\lambda+2 \mu}{2 \mu(\lambda+\mu)} a^{3} \Delta p \frac{D}{\left(r^{2}+D^{2}\right)^{3 / 2}},
$$

where $\lambda$ and $\mu$ are Lame's constants, $a$ the radius of the cavity, $D$ its mean depth, and $\Delta p$ the pressure change acting on the cavity.

Assuming that Mogi's process took place under the Izu uplift region, a model best-fitting to the GSI leveling data indicates $D=10 \mathrm{~km}$, as shown in Fig. 3. Taking $\lambda=\mu=0.33 \times 10^{12} \mathrm{dyn} / \mathrm{cm}^{2}$, we conclude $a=2 \mathrm{~km}$ for $\Delta p=1,000$ bars. Such a large pressure change may be plausible in this case on the basis of the fact that pressure reaches 2,000 bars at the time of volcanic eruption.

Gravity change $\Delta g$ for the Mogi model consists of four terms. The first term has the free-air rate $\beta$. The second is approximately equal to the Bouguer attraction of uplifted mass. The density change in the crust around the spherical cavity leads the third term. The final one corresponds to a volume increase of the cavity due to the pressure change $\Delta p$, assuming that the volume increase as a spherical shell with a thickness of $a \Delta p / 4 \mu$. Summing up these terms, the ratio of the total gravity change to the elevation change becomes

$$
\frac{\Delta g}{\Delta h}=-\beta+\frac{2 \pi G \rho(\lambda+\mu)}{\lambda+2 \mu},
$$

where $G$ is Newton's gravitational constant and $\rho$ is the mean density of the volume increase.

Equation (2) indicates that the ratio does not depend on the mean density of the crust but that of the volume increase. If the volume increase is immediately filled with a gaseous material, we take $\rho=0$, so that the righthand side of Eq. (2) becomes $-\beta$, the free-air rate. If the volume increase is filled with groundwater, gravity decreases at a rate of $-0.2807 \mathrm{mgal} / \mathrm{m}$ assuming that $\rho=1$ and $\lambda=\mu$. An intrusion with a granitic material of density $\rho=2.67 \mathrm{~g} / \mathrm{cm}^{3}$ makes gravity decreasing at a rate of $-0.2341 \mathrm{mgal} / \mathrm{m}$, which is slightly different from the Bouguer rate.

The fact that the present uplift has the free-air rate suggests that its possible cause can be a pressure increase of volcanic gas around a magma chamber. The swarm sources are mainly distributed along a volcanic belt passing through Mt.

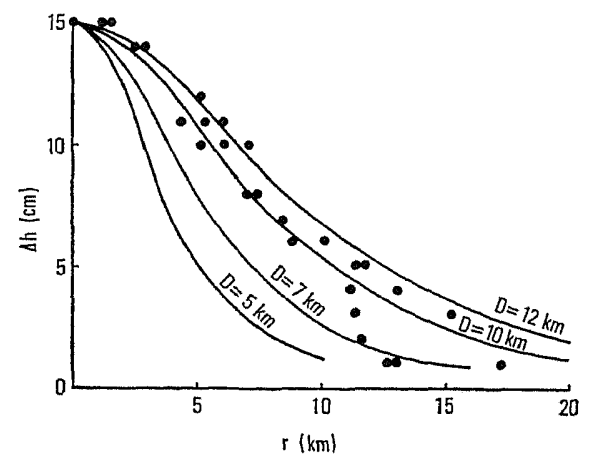

Fig. 3. Mogi-model fits to the Izu gravitychange-data. 
Togasa at depths of 1 to $9 \mathrm{~km}$. The swarm can be explained as the formation of new fissures in the surrounded rocks due to the gas pressure increase. As an inhomogeneity within the old intrusive rocks, the volcanic belt provided sites for stress concentration.

It is presumed from sea-bottom topography that there is a branch of the Nankai Trough off the eastern coastline of Izu Peninsula. This may be a thrust formed by the westward motion of the Philippine-Sea plate. The thrusting motion also produces such an uplift as presently appeared in Izu Peninsula, but not compatible with the free-air rate gravity decrease. According to the gravity change data during the 1964 Alaska earthquake (BARNES, 1966), the Bouguer relationship must exist in a thrusting area. This is the reason that the author adopts the volcanic origin for the present uplift. However, in case that a dry dilatant expansion is accompanied with the thrusting motion, the gravity change rate may fall closer to the free-air than to the Bouguer gradient.

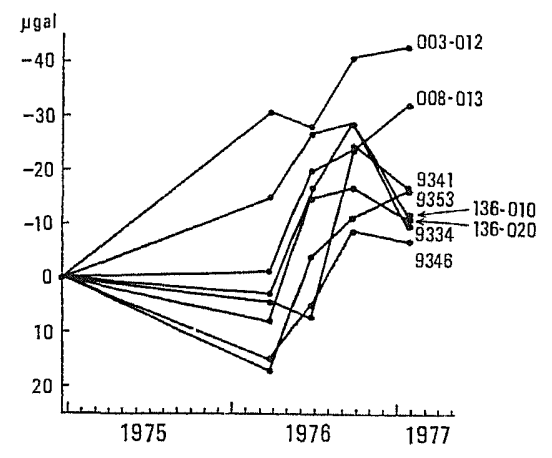

Fig. 4. Temporal changes in gravity in microgals. The numbers to the right of each curve are bench mark numbers.

The Izu crust ceased uplifting as the swarm activity became feeble in the fall of 1976. The last precise survey found that, as shown in Fig. 4, gravity has still kept decreasing in the central part of the uplift region but has turned into increasing in the surrounded part.

\section{Tidal Gravity Change during Earthquake}

At the time of the 1974 Izu Hanto-oki earthquake, an Askania Tidal Gravimeter was working at the Shirahama Maritime Observatory, which is located very close to the epicentral region. We found that the gravity-tidal factor, i.e., the ratio of the observed tidal amplitude to the theoretical one, had behaved very anomalously during about one month after the earthquake occurrence. The change in dailymean tidal factor ranged from 1.1 to 1.6 around its mean value of 1.25 (see Fig. 5), so that we suspected such a large change might be due to a kind of instrumental errors caused by the seismic shock.

There are two tide gauge stations along the eastern coast of Izu Peninsula, Koina and Ito Stations. The former is very close to the southern tip of Izu Peninsula, about 


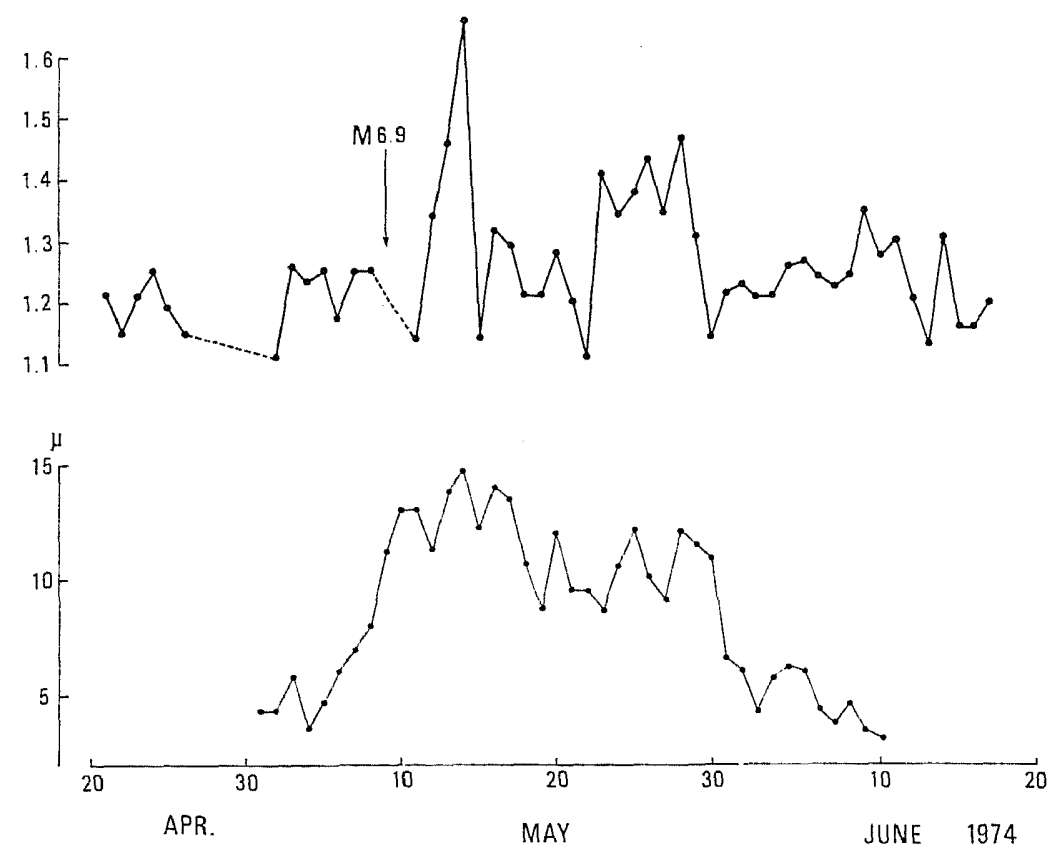

Fig. 5. Daily-mean gravity tidal factor (top) and maximum amplitude of volcanic tremor: in microns (bottom: after NAKAMURA and TAZAWA, 1974)

$15 \mathrm{~km}$ apart from the observatory. The profile of gravity-tidal factor change seems to be quite different from the tide gauge data obtained at these stations.

A seismometer established near the crater of Volcano Mihara, Oshima Island, about $40 \mathrm{~km}$ distant from Izu Peninsula, is always watching volcanic tremors for disaster prevention. Volcanic tremor is due to the oscillation of magmatic gas or due to the crater-wall falldown, so that change in the maximum amplitude of volcanic tremor indicates change in level of the magma head. At the time of the 1974 Izu Hanto-oki earthquake, the seismometer record indicated that the volcanic tremor became abnormally larger. It is noticeable in Fig. 5 that the abnormal tremor had already started before the earthquake occurrence. This fact may imply that, just as water level of a deep well rises up before a large earthquake, the preseismic crustal compression changes volume of the magma reservoir to push the magma head up. KANAMORI (1972) reported preseismic activities of Volcano Mihara became violent before the 1923 Kanto and the 1953 Boso-oki earthquakes.

The interesting point of Fig. 5 is the fact that the abnormal tidal-factor change (top) seems to be correlated with the volcanic tremor (bottom), i.e., the maximums and the minimums of the top correspond respectively to those of the bottom. Both the postseismic abnormal states recovered in the beginning of July about one month after the earthquake occurrence.

An ocean-tidal loading effect on the gravity field may be negligibly small, and the fluctuation of vertical component of the water-mass attraction may also be in 
the order of $1 \mu \mathrm{gal}$ at the gravity station as estimated from the location of the station. Though the present speculation still involves ambiguous points, we suppose the tidal data include some important information of co- and post-seismic changes in the internal compressive stress in the crust. Should the preseismic tidal change exist, the tide gravimetry equipped with a microcomputer system could easily monitor a large earthquake.

\section{Strategy for Gravity-Change Detection}

The value of gravimeter surveys for gravity-change detection lies in the fact that gravity change roughly indicates elevation change. Gravity can cover a broad area much faster than leveling. Even in a mountainous region, gravity coverage can easily be established as far as paved roads extend, although the gravimeter transportation along a non-paved road sometimes causes an irregular drift. Monitoring of preseismic uplift by repetition survey of leveling can be effectively replaced by the gravity method. Gravity reconnaissance patrols can search nationwide for a gravity decrease, under good base-station control. If one of them finds an irregular gravitydecreasing area, leveling parties can be dispatched to set up a detailed survey network there for detecting the corresponding crustal uplift.

Another application of gravimetry is for revealing some information about the mass changes accompanying crustal movement by comparing with level-change data. As stated in the previous section, the relation between gravity and elevation changes is very useful in estimating underground mass-changes throughout earthquake activities. If gravity change should exceed $50 \mu$ gals, it would be highly possible to distinguish either the free-air or the Bouguer gradients.

The good base-station control is essential to accurate gravity-change detection. The ERI future project is the establishment of base stations distribute nationwide, where tidal gravimeters are set for continuously recording changes in gravity, well controlled by a portable absolute gravimetry apparatus on patrol with an accuracy of a few microgals. For a detailed survey over an uplift area, the absolute apparatus is fixed at a nearby base station for checking the relative gravimetry. The ERI has constructed a small-sized apparatus of free-falling type for absolute gravity determination. The accuracy of measurement reached about $10 \mu$ gals in the underground laboratory of the Matsushiro Meteorological Observatory. Another portable apparatus is now being constructed for a patrol use.

\section{REFERENCES}

Barnes, D. F., Gravity changes during the Alaska Earthquake, J. Geophys. Res., 71, 451-456, 1966.

FuJI, Y., Gravity change in the shock area of the Niigata Earthquake, 16 Jun. 1964, Zishin, (J. Seismol. Soc. Japan) ii, 19, 200-216, 1966 (in Japanese).

Fuji, Y., Y. HASEgAwa, and M. MotTAmed, Gravity change and crustal deformation accompanied with the Matsushiro Swarm Earthquakes, Bull. Geogr. Surv. Inst., 20, 151-174, 1974.

Fujita, N. and Y. Fujir, Gravity change in Japan, J. Geod. Soc. Japan, 20, 77-79, 1974. 
ICHINoHe, T., Study on change of gravity with time, II. Repeated gravity surveys in the Kinki district, Mem. Coll. Sci., Univ. Kyoto, Ser. A, 27, 317-334, 1955.

IIDA, K., M. HAYAKAWA, and K. KATAYOSE, Changes of gravity difference between Imaichi and Niikko owing to the "Imaichi Earthquake," Bull. Geol. Surv. Japan, 1, 136-137, 1950 (in Japanese).

IIDA, K., M. HAYAKAWA, and K. KATAYOSE, Gravity change according to the eruption of Volcano Mihara, Ooshima Island in 1950 and 1951, Chigaku-Zasshi (J. Geogr.), 60, 133-136, 1951 (in Japanese).

Isнiмото, M., Jishin ni kankeishite juryoku wa henkasuruka, Zishin (J. Seismol. Soc. Japan), 1, 241249, 1929 (in Japanese).

IzUtUYA, S., Revised results of levelling surveys during the Matsushiro Earthquake Swarm, Bull. Earthq. Res. Inst., 50, 273-280, 1975 (in Japanese)

JitsukawA, A. and H. TAJima, Gravity surveys in the area of the Northern Miyagi Earthquake, Bull. Earthq. Res. Inst., 40, 649-652, 1962 (in Japanese).

KANAMORI, H., Relation between tectonic stress, great earthquakes and earthquake swarms, Tectonophysics, 14, 1-12, 1972.

Kisslinger, C., Processes during the Matsushiro Earthquake Swarm as revealed by leveling, gravity and spring-flow observations, Geology, 3, 57-62, 1975.

MoGr, K., Relations between the eruptions of various volcanoes and deformations of the ground surfaces around them, Bull. Earthq. Res. Inst., 36, 99-134, 1958.

NAKAMURA, K. and K. TAzAWA, A physical interpretation for correlation between 1974 Izu-Hantooki earthquake and a minor eruption of Mihara-yama, Izu-Oshima, Kazan, 19, 159-160, 1974 (in Japanese).

Nur, A., The Matsushiro, Japan, earthquake swarm: Confirmation of the dilatancy-fluid diffusion model, Geology, 2, 217-221, 1974.

Rikitake, T., Earthquake prediction studies in Japan, Geophys. Surv., 1, 4-26, 1972.

Satomura, M. and I. Nakagawa, Secular change of gravity near Lake Biwa-ko, Contr. Geophys. Inst., Kyoto Univ., 12, 101-115, 1972.

StUART, W.D. and M.J.S. Johnston, Intrusive origin of the Matsushiro Earthquake Swarm, Geology, 3, 63-67, 1975.

TAJiMA, H. and S. IzUtUYA, Gravity changes during and after the Matsushiro Earthquake Swarm, J. Geod. Soc. Japan, 20, 153-168, 1974 (in Japanese).

TSUBOKAWA, I., A. OKADA, S. IZUTUYA, Y. ITo, and K. KaDONo, Levelling resurvey associated with the area of Matsushiro Earthquake Swarm (2), Bull. Earthq. Res. Inst., 46, 417-429, 1968 (in Japanese). 